\title{
Sudden unexpected fatal encephalopathy in adults with OTC gene mutations-Clues for early diagnosis and timely treatment
}

\author{
Catia Cavicchi ${ }^{1}$, Maria Alice Donati ${ }^{2}$, Rossella Parini ${ }^{3}$, Miriam Rigoldi ${ }^{3}$, Mauro Bernardi ${ }^{4}$, Francesca Orfei ${ }^{5}$, \\ Nicolò Gentiloni Silveri ${ }^{6}$, Aniello Colasante ${ }^{7}$, Silvia Funghini ${ }^{8}$, Serena Catarzi ${ }^{1}$, Elisabetta Pasquini ${ }^{2}$, Giancarlo la Marca ${ }^{8,9}$, \\ Sean David Mooney ${ }^{10}$, Renzo Guerrini ${ }^{9,11}$ and Amelia Morrone ${ }^{1,9^{*}}$
}

\begin{abstract}
Background: X-linked Ornithine Transcarbamylase deficiency (OTCD) is often unrecognized in adults, as clinical manifestations are non-specific, often episodic and unmasked by precipitants, and laboratory findings can be normal outside the acute phase. It may thus be associated with significant mortality if not promptly recognized and treated. The aim of this study was to provide clues for recognition of OTCD in adults and analyze the environmental factors that, interacting with OTC gene mutations, might have triggered acute clinical manifestations.

Methods: We carried out a clinical, biochemical and molecular study on five unrelated adult patients (one female and four males) with late onset OTCD, who presented to the Emergency Department (ED) with initial fatal encephalopathy. The molecular study consisted of OTC gene sequencing in the probands and family members and in silico characterization of the newly detected mutations.

Results: We identified two new, c.119G>T (p.Arg40Leu) and c.314G>A (p.Gly105Glu), and three known OTC mutations. Both new mutations were predicted to cause a structural destabilization, correlating with late onset OTCD. We also identified, among the family members, 8 heterozygous females and 2 hemizygous asymptomatic males. Patients' histories revealed potential environmental triggering factors, including steroid treatment, chemotherapy, diet changes and hormone therapy for in vitro fertilization.

Conclusions: This report raises awareness of the ED medical staff in considering OTCD in the differential diagnosis of sudden neurological and behavioural disorders associated with hyperammonemia at any age and in both genders. It also widens the knowledge about combined effect of genetic and environmental factors in determining the phenotypic expression of OTCD.
\end{abstract}

Keywords: Urea Cycle Disorders (UCD), Ornithine transcarbamylase deficiency (OTCD), Late onset OTCD, OTC gene mutations, Hyperammonemic encephalopathy, Environmental triggering factors for hyperammonemia

\footnotetext{
* Correspondence: amelia.morrone@unifi.it

${ }^{1}$ Molecular and Cell Biology Laboratory, Pediatric Neurology Unit and

Laboratories, Neuroscience Department, A. Meyer Children's Hospital, Viale

Pieraccini 24, 50139 Florence, Italy

${ }^{9}$ Department of Neurosciences, Psychology, Pharmacology and Child Health,

University of Florence, Florence, Italy

Full list of author information is available at the end of the article
} 


\section{Background}

Ornithine transcarbamylase deficiency (OTCD; OMIM 311250), the most common urea cycle disorder (UCD), is caused by a defect of the mitochondrial ornithine transcarbamylase (OTC, EC 2.1.3.3). The mature OTC enzyme, a trimer, catalyses the synthesis of citrulline from carbamyl phosphate $(\mathrm{CP})$ and ornithine $(\mathrm{ORN})$ in the liver and small intestine [1].

OTCD is an X-linked disorder due to deleterious mutations in the OTC gene in Xp21.1 and is characterized by high molecular heterogeneity with about 435 mutations having been described (HGMD: http://www.biobaseinternational.com/product/hgmd). Severe OTC gene mutations with no residual enzyme activity in hemizygous males lead to hyperammonemic coma in the neonatal period or in early infancy, which is often fatal. Some affected males may, however, exhibit a delayed onset of the disease, the so called "late onset OTCD" (LO-OTCD) [2]. The number of reported LO-OTCD patients is increasing [3], but only a few had remained essentially asymptomatic until acute onset in adulthood. In hemizygous male patients the phenotype is determined by several conditions, including the type of mutation but also other yet unknown factors such as environment and/or other genes. In heterozygous females phenotypic severity is also influenced by the X-inactivation pattern [1].

Without early diagnosis and intervention, the prognosis of OTCD with acute hyperammonemia is poor. The emergency management of hyperammonemia is based on: a) reversal of the catabolic state through glucose supplementation and halted protein intake, b) pharmacological removal of ammonia by sodium benzoate, sodium phenylacetate or sodium phenylbutyrate administration and c) extracorporeal detoxification of ammonia by dialysis $[4,5]$. L-arginine and/or L-citrulline supplementation promote ammonia excretion through the urea cycle [4]. Hypothermia may be a neuroprotective measure, but its efficacy has not yet been proven in randomized controlled trials [6]. Guidelines for the diagnosis and management of UCD have been recently drawn up in order to provide a general consensus to guide practitioners and set standards of care [4].

We report a clinical, biochemical and molecular study of five adults with OTCD who developed de novo fatal hyperammonemic encephalopathy. We also present the in silico characterization of the newly detected OTC gene mutations and discuss the environmental events that, interacting with $O T C$ mutations, might have triggered acute clinical manifestations.

\section{Methods}

\section{Patients}

Patients were adults referred to our diagnostic laboratory because of clinical suspicion of a UCD, and their relatives. Informed consent to the investigation, according to the
Declaration of Helsinki and approved by the Human Research Ethics Committee of the Meyer's University Hospital, was obtained from all subjects.

\section{Biochemical assays}

Plasma amino acid analysis was performed by ion-exchange chromatography on a Biochrom 30 amino acid analyzer (Cambridge, UK) using the manufacturer's standard protocol.

Quantification of orotic acid in urine was performed by LC-MS/MS (Toronto, Canada) as previously described [7].

\section{Detection of OTC gene mutations}

Genomic DNA was isolated from peripheral blood using a QIAsymphony instrument as recommended by the manufacturer (Qiagen, Hilden, Germany). The entire coding region and intron-exon boundaries of the OTC gene were amplified by PCR as previously reported [8]. PCR fragments were separated on a $2 \%$ agarose gel, visualized with a UV transilluminator and then purified using Exo-SAPIT (USB Corporation, Cleveland, OH, U.S.A).

Mutation analysis was performed by direct sequencing of the double-stranded purified products using the BigDye Terminator v1.1 Cycle Sequencing Kit (Applied Biosystems, Foster City, U.S.A.). Sequencing reactions were purified using Sephadex G-50 Fine (GE Healthcare, Little Chalfont, UK) and capillary electrophoresis was performed on ABI PRISM 3130 Genetic Analyser (Applied Biosystems) as recommended by the manufacturer.

All mutations are described according to guidelines of the Human Genomic Variation Society (HGVS) (http:// www.hgvs.org/mutnomen/) and using the NM_000531.3 and NP_000522.3 reference sequences (http://www.ncbi. nlm.nih.gov/gene/).

\section{Screening of new OTC mutations}

The Human Gene Mutation Database (HGMD) (http:// www.biobase-international.com/product/hgmd) was analyzed for investigating the novelty of mutations identified. The two new point mutations were subsequently examined in the 1000 Genomes project database (http:// browser.1000genomes.org/index.html). In addition, we screened by sequencing analysis the OTC gene of 100 DNA samples from healthy males to estimate the frequency of new mutations in the Italian population.

\section{Bioinformatic analyses of new OTC mutations}

We downloaded the crystal structure for human OTC protein [PDB: $1 \mathrm{OTH}$ ] for structural analysis of the mutant OTC enzyme. The 2D structure boundaries and solvent accessibility were calculated with the Stride program [9].

Stability changes in OTC protein introduced by mutations were predicted by IMutant 2.0 [10]. Structure- 
based predictions were performed in silico at $\mathrm{pH} 7$ and $37^{\circ} \mathrm{C}$.

Knowledge about catalytic residues and substrate binding sites was obtained from the literature $[11,12]$. Effects of mutations on the trimeric protein were predicted based on PDB entry 1FVO. Inter-residue contacts were studied with the CSU program [13].

For conservation analysis, 18 homologous sequences (10 from eukaryotes and 8 from bacteria) were aligned by MAFFT E-INS-I [14]. Conservation scores were obtained from the ConSurf program (Bayesian paradigm) [15].

The pathogenicity and functional effects of the new OTC mutations were evaluated by SNAP (http://rostlab.org/ services/snap/), PolyPhen-2 (http://genetics.bwh.harvard. edu/pph2/) and MutPred (http://mutpred.mutdb.org/). The probability threshold for pathogenicity was set to the default value 0.05 for all tools.

\section{Results}

\section{Clinical and biochemical investigation}

Four Italian men (Pts 1 to 4) and one woman (Pt 5), aged 21 to 66 years, developed initial and fatal hyperammonemic encephalopathy due to undiagnosed LOOTCD. Their main clinical and laboratory findings are summarized in Tables 1 and 2. Detailed case reports are available in Additional file 1: Text S1.

At the time of the acute episodes, none of the patients had a family history of metabolic disorders or had previous episodes of altered mental status. Interestingly, three patients reported preferring a low-protein diet with large amounts of vegetables.

The clinical course of acute expression of symptoms was similar in all patients, starting with gastrointestinal symptoms and/or impaired awareness, rapidly evolving into deterioration of the mental status and coma within 5 days from onset. Noticeably, in addition to hyperammonemia, hypertransaminasemia and respiratory alkalosis were observed in all patients.

The suspicion of OTCD was biochemically based on altered amino acid profiles and orotic aciduria, which is crucial for distinguishing OTCD from carbamoyl phosphate synthetase I (CPS1) and N-acetylglutamate synthase (NAGS) deficiencies.

After clinical/biochemical suspicion of UCD was established, emergency management of hyperammonemia was started in $4 / 5$ patients, but although in $3 / 5$ patients ammonia levels returned to normal after UCD therapy, exitus ensued.

\section{Molecular investigation}

We confirmed OTCD in all patients by post-mortem OTC sequence analysis. We identified two novel mutations, c.119G > T (p.Arg40Leu) and c.314G > A (p.Gly105$\mathrm{Glu}$ ), and three previously reported mutations, c.119G > A
(p.Arg40His), c.622G > A (p.Ala208Thr) and c.829C > T (p.Arg277Trp). The results of molecular and computational analysis are summarized in Table 3.

None of the new genetic variants was present in the 1000 Genomes Project database or in the Italian control population, suggesting that they are likely to be diseasecausing mutations. Noticeably, all three pathogenicity prediction tools, e.g. SNAP, PolyPhen-2 and MutPred, consistently classified both new variants as pathogenic (see Additional file 2: Table S2).

The novel c.119G > T (p.Arg40Leu) mutation, identified at a hemizygous level in Pt 1 , affects a CpG dinucleotide in the exon which is also involved in two other known mutations, the c.118C $>\mathrm{T}$ (p.Arg40Cys) [16] and c.119G > A (p.Arg40His) [17]. The Arg 40 is a conserved residue of the polar/CP binding domain (residues 34-168 and 345-354) [11], is not in contact with the active site and its side chain is exposed to the surface (Figure 1A).

The novel c.314G > A (p.Gly105Glu) mutation was identified at the hemizygous level in Pt 3 . The same nucleotide is also involved in the c.314G $>\mathrm{T}$ (p.Gly105Val) mutation that had previously been identified in a female with OCTD [18]. The Gly 105 is a conserved residue mapping in a turn of polar/CP binding domain of the OTC protein [11]. In the trimeric OTC enzyme the 105 position is located on the top of trimer interface and the three amino acids would be close to each other in the quaternary structure (Figure 1B).

All the known c.119G > A (p.Arg40His), c.622G > A (p. Ala208Thr) and c.829C $>$ T (p.Arg277Trp) mutations have been previously reported in OTCD patients with residual enzymatic activity $[17,19,20]$.

After the probands' characterization the molecular study of the OTC gene was extended to family members and led to identification of 8 heterozygous females and 2 additional hemizygous asymptomatic males (Table 3).

\section{Retrospective analysis for potential environmental triggering factors}

The retrospective analysis of the patients' histories revealed a number of precipitating environmental factors, including therapy with steroids (Pt 1 ), diet changes implying poor feeding after dental surgery (Pt 2) and increased dietary protein intake plus food additives (Pt 3), chemotherapy (Pt 4) and hormone therapy for in vitro fertilization (Pt 5).

\section{Discussion}

\section{Clinical and biochemical clues}

OTCD is traditionally identified in pediatric patients [21], while late-onset presentations may remain latent for many years and often go unrecognized. As a consequence, mortality rates may be high if they are not 
Table 1 Clinical findings of adult OTCD patients with fatal encephalopathy

\begin{tabular}{|c|c|c|c|c|c|}
\hline & Pt 1 (M) & Pt 2 (M) & Pt 3 (M) & Pt 4 (M) & Pt 5 (F) \\
\hline \multicolumn{6}{|l|}{ ACUTE EPISODE } \\
\hline Age at fatal acute episode & $45 y$ & $44 y$ & 21 y & $66 y$ & 34 y \\
\hline Duration of fatal episode & $9 d$ & $30 d$ & $15 d$ & $5 d$ & $22 d$ \\
\hline Duration of coma & $7 d$ & $1 \mathrm{~d}$ (first coma); $7 \mathrm{~d}$ (second coma) & $12 d$ & $2 d$ & $20 d$ \\
\hline $\begin{array}{l}\text { FAMILY HISTORY OF } \\
\text { METABOLIC DISORDERS }\end{array}$ & Negative & Negative & Negative & Negative & Negative \\
\hline PAST MEDICAL HISTORY & $\begin{array}{l}\text { Cholecystectomy; Crohn disease; } \\
\text { Carpal tunnel syndrome; Sciatica }\end{array}$ & $\begin{array}{l}\text { Chronic Hepatitis B with fluctuating } \\
\text { hypertransaminasemia and prothrombin } \\
\text { deficiency }\end{array}$ & Negative & $\begin{array}{l}\text { Hypertension; Colon cancer } \\
\text { (colectomy and oxaliplatin and } \\
\text { capecitabine drugs); Hiccup after } \\
\text { chemotherapy }\end{array}$ & $\begin{array}{l}\text { Drowsiness during } \\
\text { menstruation }\end{array}$ \\
\hline DIET PRACTISE & Regular & Vegetarian & Diet rich in vegetables & Diet rich in vegetables & Regular \\
\hline $\begin{array}{l}\text { PROBABLE TRIGGERING } \\
\text { EVENT }\end{array}$ & Cortisone therapy for joint pains & $\begin{array}{l}\text { Diet change and poor feeding } \\
\text { ( } 8 \mathrm{~kg} \text { lost in a month) after dental surgery }\end{array}$ & $\begin{array}{l}\text { Diet change: a meal of fish in } \\
\text { a Chinese restaurant }\end{array}$ & $\begin{array}{l}\text { Chemotherapy (Oxaliplatin, } \\
\text { Capecitabine) }\end{array}$ & $\begin{array}{l}\text { Infertility hormone } \\
\text { therapy and ICSI-ET, } \\
\text { but without an ongoing } \\
\text { pregnancy }\end{array}$ \\
\hline MISDIAGNOSIS AT ONSET & $\begin{array}{l}\text { Depression; Unspecified } \\
\text { hepatopathy }\end{array}$ & $\begin{array}{l}\text { Infectious disease; Intestinal } \\
\text { pseudo-obstruction; Portosystemic shunts }\end{array}$ & $\begin{array}{l}\text { Poisoning; Infectious diseases; } \\
\text { Drug abuse }\end{array}$ & $\begin{array}{l}\text { Poisoning; Ischemia; Cancer; } \\
\text { Hepatitis }\end{array}$ & Narcolepsy; Cancer \\
\hline \multicolumn{6}{|l|}{$\begin{array}{l}\text { SIGN AND SYMTOMS OF } \\
\text { ACUTE EPISODE }\end{array}$} \\
\hline Abdominal pain/Nomiting & No/Yes & Yes/Yes & Yes/Yes & No/No & No/No \\
\hline Headache/Nertigo & Yes/Yes & No/Yes & No/No & No/Yes & $\mathrm{No} / \mathrm{No}$ \\
\hline Fever & No & Yes & No & No & Yes \\
\hline Food refusal & Yes & Yes & No & No & No \\
\hline Seizures & No & Yes & No & Yes & Yes \\
\hline Hepatomegaly & No & No & No & Mild & No \\
\hline Consciousness disturbances & $\begin{array}{l}\text { Confusion; Drowsiness; Coma } \\
\text { ( } 2 \text { d after onset) }\end{array}$ & $\begin{array}{l}\text { Irritability; Confusion; Coma lasting } \\
24 \text { hours ( } 5 \text { d after onset); Subsequent } \\
\text { coma ( } 20 \mathrm{~d} \text { after) }\end{array}$ & $\begin{array}{l}\text { Confusion; Drowsiness; Coma } \\
\text { (3 d after onset) }\end{array}$ & $\begin{array}{l}\text { Slurred speech; Confusion; } \\
\text { Hallucinations; Drowsiness; } \\
\text { Coma (3 d after onset) }\end{array}$ & $\begin{array}{l}\text { Drowsiness; Coma } \\
\text { (2 d after onset) }\end{array}$ \\
\hline
\end{tabular}

Abbreviations: $M$ male, $F$ female, $y$ years, $d$ days, ICSI-ET intra cytoplasmatic sperm injection - embryo transfer. 
Table 2 Laboratory findings and therapy of adult OTCD patients with fatal encephalopathy

\begin{tabular}{|c|c|c|c|c|c|}
\hline & Pt 1 (M) & Pt 2 (M) & Pt $3(M)$ & Pt 4 (M) & Pt 5 (F) \\
\hline \multicolumn{6}{|l|}{ LABORATORY DATA } \\
\hline Total bilirubin (mg/dl, n.v. <1.2) & 1.4 & 5.4 & 7.9 & Normal & 2.8 \\
\hline ALT; AST (U/l, n.v.<40) & $62 ; 55$ & $467 ; 226$ & $128 ; 84$ & $127 ; 97$ & $81 ; 95$ \\
\hline $\begin{array}{l}\text { Ammonia (first measurement - maximum value, } \mu \mathrm{mol} / \mathrm{l} \text {, } \\
\text { n.v. } 50-80 \text { ) }\end{array}$ & $153-411$ & $369-845$ & $156-377$ & $251-1145$ & 362-901 \\
\hline $\begin{array}{l}\text { Respiratory alkalosis (n.v.: blood pH 7.35-7.45, } \mathrm{pCO}_{2} 35- \\
45 \mathrm{mmHg}, \mathrm{pO}_{2} 75-100 \mathrm{mmHg} \text { ) }\end{array}$ & blood pH 7.47, -, - & $\begin{array}{l}\text { blood } \mathrm{pH} 7.54, \mathrm{pCO}_{2} 30 \\
\mathrm{pO}_{2} 142\end{array}$ & $\begin{array}{l}\text { blood } \mathrm{pH} 7.45 \\
\mathrm{pCO}_{2} 32 \\
\mathrm{pO}_{2} 202\end{array}$ & $\begin{array}{l}\text { blood } \mathrm{pH} 7.51 \\
\mathrm{pCO}_{2} 27, \mathrm{pO}_{2} 223\end{array}$ & blood pH 7.51, $\mathrm{pCO}_{2} 26, \mathrm{pO}_{2} 274$ \\
\hline${ }^{\mathrm{P}}$ Glutamine ( $\mu \mathrm{mol} / \mathrm{l}$, n.v. 399-823) & 2006 & 4580 & Normal & 1680 & 1060 \\
\hline${ }^{P}$ Citrulline ( $\mu \mathrm{mol} / /$, n.v. 17-53) & Normal & Normal & 14 & 3 & 10 \\
\hline${ }^{\text {PLysine; }}{ }^{P}$ Proline ( $\mu \mathrm{mol} / \mathrm{l}$, n.v. $\left.105-236 ; 117-332\right)$ & 702; Normal & $900 ; 667$ & - & - & 462; Normal \\
\hline UOrotic acid excretion ( $\mathrm{mmol} / \mathrm{mol}$ creatinine, n.v. 0.2-1.1) & 378 & 34 & Normal & 234 & 136 \\
\hline Neuroimaging & $\begin{array}{l}\text { Normal at onset }(C T) \text {; } \\
\text { Cerebral edema } \\
\text { (CT, } 2 \text { d later) }\end{array}$ & $\begin{array}{l}\text { Normal at onset }(C T) \text {; } \\
\text { Cerebral edema } \\
\text { (CT, 3rd d of the } \\
\text { second coma) }\end{array}$ & $\begin{array}{l}\text { Normal at onset }(\mathrm{CT}) \text {; } \\
\text { Cerebral edema } \\
\text { (CT, } 3 \text { d later) }\end{array}$ & $\begin{array}{l}\text { Normal at onset } \\
\text { (CT and MRI) }\end{array}$ & $\begin{array}{l}\text { Normal at onset (CT); Cerebral } \\
\text { edema (MRI, } 2 \text { d later) }\end{array}$ \\
\hline THERAPY & $\begin{array}{l}\text { PHN; Antibiotics, BCAA } \\
\text { infusion and lactulose }\end{array}$ & $\begin{array}{l}\text { PHN; BCAA infusion } \\
\text { (first coma); Mannitol; } \\
\text { Propofol and thiopental; } \\
\text { UCD therapy: stop protein } \\
\text { intake, high caloric intake, } \\
\text { L-Arg and CWHDF }\end{array}$ & $\begin{array}{l}\text { PHN, BCAA infusion; } \\
\text { Mannitol; Lactulose; } \\
\text { Antibiotics; UCD therapy: } \\
\text { SB, SPB and L-Arg }\end{array}$ & $\begin{array}{l}\text { PHN; Phenytoin, } \\
\text { thiopental and curare; } \\
\text { UCD therapy: SB, SPB, } \\
\text { L-Arg and CWHDF }\end{array}$ & $\begin{array}{l}\text { PHN; Midazolam, metamizole } \\
\text { and hypothermia; BCAA infusion; } \\
\text { UCD therapy: stop protein intake, } \\
\text { high caloric intake, SPB, L-Arg and HD }\end{array}$ \\
\hline Date of starting UCD therapy (days from onset) & None & 2nd d from second coma & $3 r d d$ & $3 r d d$ & 7th $d$ \\
\hline Ammonia after UCD therapy & None & Never normalized & Normal & Normal & Normal \\
\hline Time for normalisation of ammonia under UCD therapy & None & None & $4 d$ & $1 \mathrm{~d}$ and a half & $4 d$ \\
\hline
\end{tabular}

Abbreviations: ALT alanine aminotransferase, AST aspartate aminotransferase, - not available, ${ }^{p}$ plasma, ${ }^{u}$ urine, $C T$ computed tomography, $d$ days, $M R I$ magnetic resonance imaging, $P H N$ parenteral hydration and nutrition, $B C A A$ branched chain amino acids, UCD urea cycle disorder, L-Arg L-arginine, CVVHDF continuous veno venous hemodiafiltration, SB sodium benzoate, SPB sodium phenylbutyrate, HD hemodialysis. 
Table 3 OTC gene mutations identified in adult OTCD patients with fatal encephalopathy

\begin{tabular}{|c|c|c|c|c|c|c|}
\hline $\begin{array}{l}\text { Patient } \\
\text { (sex; origin) }\end{array}$ & Mutation & Exon & Functional domain & Comment & $\begin{array}{l}\text { Mutation } \\
\text { reference }\end{array}$ & Genetic family testing \\
\hline Pt 1 (M; Italy) & $\begin{array}{l}\text { c.119G > T } \\
\text { (p.Arg40Leu) }\end{array}$ & 2 & Polar/CP binding domain (S1) & CpG dinucleotide & $\begin{array}{l}\text { This } \\
\text { report }\end{array}$ & $\begin{array}{l}\text { Three HT females: mother }(76 \mathrm{y}) \text {, } \\
\text { two nieces ( } 13 \text { and } 22 \mathrm{y}) \text {; } \\
\text { HM brother }(50 \mathrm{y}) \text {; WT sister }\end{array}$ \\
\hline $\begin{array}{l}\text { Pt } 2 \text { (M; Italy } \\
\text { and Japan) }\end{array}$ & $\begin{array}{l}\text { c. } 119 \mathrm{G}>\mathrm{A} \\
\text { (p.Arg40His) }\end{array}$ & 2 & Polar/CP binding domain (S1) & $\begin{array}{l}\text { CpG dinucleotide; protein } \\
\text { degradation under certain } \\
\text { conditions; reported OTC } \\
\text { activity } 6 \%\end{array}$ & [17] & Not performed \\
\hline Pt 3 (M; Italy) & $\begin{array}{l}\text { c.314G > A } \\
\text { (p.Gly105Glu) }\end{array}$ & 4 & Polar/CP binding domain (turn) & - & $\begin{array}{l}\text { This } \\
\text { report }\end{array}$ & $\begin{array}{l}\text { HT mother }(43 \mathrm{y}) \text {; } \\
\text { HM grandfather }(80 \mathrm{y}) \text {; } \\
\text { WT brother }\end{array}$ \\
\hline Pt 4 (M; Italy) & $\begin{array}{l}\text { c.622G > A } \\
\text { (p.Ala208Thr) }\end{array}$ & 6 & $\begin{array}{l}\text { Equatorial/ORN binding domain } \\
\text { (H6) }\end{array}$ & $\begin{array}{l}\text { CpG dinucleotide; reported } \\
\text { OTC activity } 4 \%\end{array}$ & [19] & HT daughter (36 y) \\
\hline Pt 5 (F; Italy) & $\begin{array}{l}\text { c. } 829 \mathrm{C}>\mathrm{T} \\
\text { (p.Arg277Trp) }\end{array}$ & 8 & $\begin{array}{l}\text { Equatorial/ORN binding domain } \\
(\mathrm{H} 9) \text {, flexible loop }\end{array}$ & $\begin{array}{l}\text { CpG dinucleotide; } \\
\text { increased } k_{m} \text { for ORN; } \\
\text { reported OTC activity 5\% }\end{array}$ & {$[20]$} & $\begin{array}{l}\text { Three HT females: mother }(72 \mathrm{y}) \text {, } \\
\text { sister }(42 \mathrm{y}) \text { and niece }(18 \mathrm{y}) \text {; } \\
\text { six WT females and two WT males }\end{array}$ \\
\hline
\end{tabular}

Abbreviations: $M$ male, $F$ female, $C P$ carbamyl phosphate, ORN ornithine, $S$ strand or $\beta$-sheet, $H$ a-helix, $H T$ heterozygous, $H M$ hemizygous, $W T$ wild type, $y$ years of family members at the time of the proband's acute episode.

promptly treated. An observational study of nonclassical UCD including OTCD adults has been recently reported [3]. However, no information is available indicating the number of asymptomatic adult probands, or their clinical course or the potential role of precipitant factors. Herein we report previously asymptomatic OTCD adults to provide clues that might help recognition of OTCD in adult age, and discuss the environmental factors triggering initial and fatal hyperammonemic episodes.

The patient's dietary preference for vegetables should be considered as an important clinical clue, since voluntary protein avoidance is a characteristic eating behavior that UCD patients adopt in order to avoid postprandial headache or drowsiness [22].

Special attention should be given to the biological specimen collection, since biochemical marker determination is essential for UCD diagnosis, especially during the acute episodes and also in patients with fatal outcome. In patients with acute unexplained encephalopathy is mandatory to perform blood gas analysis and plasma ammonia measurement as part of the basic work-up, even in the absence of liver dysfunction. Detection of respiratory alkalosis and hyperammonemia must address further metabolic investigations on plasma and urine to confirm or exclude UCD, without delaying the specific hyperammonemia treatment, as clinical outcome strictly correlates with the duration and peak level of hyperammonemia [4]. Analysis of plasma amino acids and urine orotic acid should be urgently performed in a specialist centre at initial detection of hyperammonemia. Glutamine levels and increased urinary orotic acid are the main biochemical markers for acute-phase OTCD. Citrulline and arginine levels are often low in LO-OTCD but may be normal outside the acute phase $[23,24]$.

In Pt 3 the normal values of both plasma glutamine and urinary orotic acid, detected at first measurement
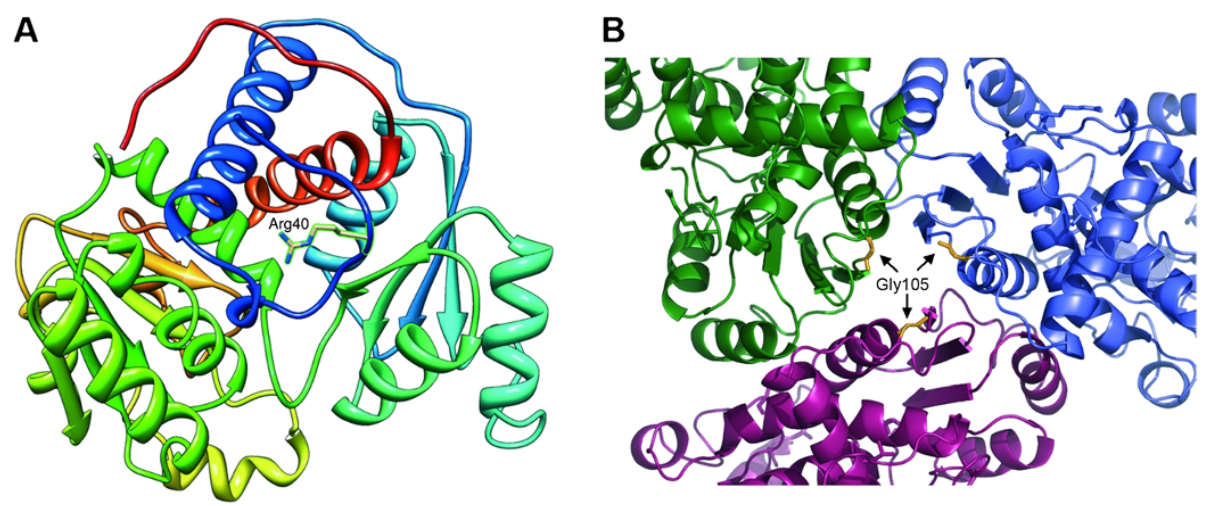

Figure 1 OTC enzyme three dimensional structure mapping the new missense variants. A) 3D visualization of the new p.Arg40Leu mutation in the OTC monomer. B) Trimeric assembly of OTC enzyme indicating position 105 involved in the new p.Gly105Glu mutation. Constituent monomers are colored green, blue and magenta and position 105 is colored yellow in each of them. 
when only mild symptoms were present, were at odds with the suspicion of OTCD, but a final OTCD diagnosis was reached through molecular analysis. In Pt 2 we found high plasma and urinary levels of lactate during his comatose state. This finding is in line with Snodgrass 2004 [25] who reported lactic acidosis only in advanced phase of OTCD.

It has been reported that during acute OTCD episodes coagulopathy may occasionally appear as a consequence of liver dysfunction [26]. More recently, it has been emphasised that coagulation abnormalities are previously unidentified complications of OTCD also in a remission state [27]. In light of these findings, a diagnosis of OTCD and other UCD should be actively sought in any child or adult presenting with coagulopathy and/or liver failure of undetermined etiologies [28]. In Pt 2 we detected prothrombin deficiency, but is unknown if it was an expression of chronic hepatitis, or of OTCD or of both. In this patient the diagnostic process was severely complicated and delayed by many misdiagnoses, such as portosystemic shunt, as frequently described by Japanese authors [29].

Hyperlysinemia and hyperprolinemia, which have been reported as negative prognostic factors for OTCD [30], have been detected in 3 patients in our series. However, hyperprolinemia in Pt 2 may be secondary to hyperlactacidemia, probably because proline oxidase is inhibited by lactic acid [31].

\section{Molecular analysis and mutational correlations to LO-OTCD}

Molecular analysis is the first choice method for confirming an OTCD diagnosis, thus it would be advantageous that the emergency department staff promptly consult a clinical biochemical geneticist or clinical geneticist, even at the initial presentation if possible (see links: http://www.orpha.net/consor/cgi-bin/index.php, https://www. eimd-registry.org/ and https://rarediseasesnetwork.epi.usf. edu/ucdc/index.htm). However, most of the OTC mutations are private and variants whose pathogenicity is unknown and sometimes difficult to ascertained are frequently found. Thus, in silico analysis, by combining different tools, may be useful for predicting variant effects.

The novel p.Arg40Leu mutation leads to destabilization of the OTC enzyme by the loss of a salt bridge or of MoRF (Molecular Recognition Feature) binding. The MoRFs represent a class of disordered regions that provide molecular recognition and binding functions to other proteins and undergo disorder-to-order transitions upon specific bindings [32]. The in silico results for p.Arg40Leu are in line with the suggestion that mutations affecting codons on the convex face of the OTC trimer, such as Arg 40, may alter the conformation of the $\mathrm{C}$-terminus and hence interfere with its interaction with other proteins or the membrane [11].

The novel p.Gly105Glu mutation leads to a destabilization of local structures because of changes in solvent accessibility and in charge and steric hindrance, finally resulting in a perturbation of the trimer assembly. Therefore, p.Gly105Glu seems to lead to a partially functional enzyme.

The known p.Arg40His, p.Ala208Thr and p.Arg277Trp mutations are also responsible for partial OTC enzyme deficiency. Although the enzymatic assay was not performed for the novel p.Arg40Leu, in silico data indicating the biochemical similitude between the two mutations $\mathrm{p}$. Arg40Leu and p.Arg40His and the comparable clinical presentation of patients carrying such mutations, suggest that p.Arg40Leu is also correlated with residual enzymatic activity and LO-OTCD.

Four out of five identified mutations affect $\mathrm{CpG}$ islands and three of them arise in arginine. Arginine has a high mutational score, likely because four of the six codons encoding it contain $\mathrm{CpG}$ dinucleotides, which represent mutational hot spots [2]. Since the novel p. Arg40Leu mutation affects the same CpG island as the known recurrent c.119G > A (p.Arg40His) mutation, it is probable that p.Arg40Leu might also occur in additional families.

\section{Correlation of OTCD unmasking with environmental factors}

The acute disease expression in the patients we reported results from a combination of genetic and environmental factors. Exposure to new environmental or stress factors may induce an unusual nitrogen load or a significant catabolic event, which can briskly affect the patients' homeostasis and interfere with residual OTC activity, making it no longer sufficient to remove the increased amount of waste nitrogen generated. Some medications may also cause hepatic toxicity and subsequent additional impairment of already overwhelmed OTC activity in the liver. The identification in the patients' families of several healthy adults of both genders harboring the same mutations as the patients, corroborates the hypothesis that these mutations cause their pathogenetic consequences only when particular environmental conditions arise.

Cortisone is a glucocorticoid hormone with many therapeutic uses. High circulating concentrations of glucocorticoids are known to have a general catabolic effect by primarily enhancing protein turnover [33]. There are at least four reports of OTCD adults who developed acute hyperammonemic coma following steroid administration [5,34-36].

Fasting and surgery are commonly considered dangerous conditions for OTCD patients since they cause metabolic stress and are often accompanied by reduced 
energy production and increased turnover of endogenous proteins [5,37-39]. Moreover, a role of high protein diets (e.g. Atkins' diet) in unmasking adult-onset OTCD has been previously described [40].

Besides a high protein intake as an obvious triggering factor in Pt 3, the possible precipitating role of monosodium glutamate (MSG) consumption, which is especially used in Asian cuisine as a flavor enhancer, could also be considered. MSG has been reported to accelerate gastric emptying of a protein-rich meal in humans, stimulating secretions from the exocrine and endocrine systems and leading to increased plasma glutamine concentrations [41]. Therefore, MSG ingested by our patient could have contributed to a more rapid overload of nitrogen and glutamine.

Chemotherapics are among the medications causing hepatic toxicity and affecting protein catabolism. Their side effects on the oro-gastrointestinal tract are indeed responsible for impairing dietary protein absorption and consequently accelerating degradation of endogenous proteins. A postchemotherapy hyperammonemic encephalopathy emulating OTCD has been described as a distinct syndrome of hyperammonemia in two young women with hepatocellular carcinoma, who resulted mutation-negative to OTC $[42,43]$. Since insertion/deletions or deep intronic mutations were not excluded, OTCD unmasked by chemotherapy could still be possible in these patients.

The precipitating environmental factor for the female patient is not obvious, but a potential role of sex hormones or hormonal drugs seems to be very likely. Menses are considered precipitants for acute hyperammonemia in UCD [44] and a relationship between sex hormones and ureagenesis in a woman with UCD has been reported [45]. At least three hypotheses might explain the OTCD unmasking in our patient: a) the physiological changes of the endometrium during the menstrual cycle, which produce large amounts of waste nitrogen and which may explain the drowsiness occurring in conjunction with menses; b) the direct action of endogenous sex hormones and/or hormonal drugs on the urea cycle by modulation of enzymatic expression and function; c) the toxic effects of infertility medication resulting in worsening of hepatic function, since these drugs are primarily metabolized in the liver.

An additional precipitant for the metabolic decompensation in our patients might have been parenteral nutrition, which provides more proteins than the patient usually expends entirely [46].

\section{Conclusions}

The diagnosis of OTCD in adults may be difficult, as clinical manifestations are non-specific and often episodic and laboratory findings can be normal outside the acute phase. Since LO-OTCD can be hidden and suddenly become symptomatic under specific environmental factors, early suspicion/diagnosis is crucial to providing effective treatment in probands and to helping prevent clinical outbursts in other family members. This report raises awareness of emergency department staff in considering OTCD in the differential diagnosis of sudden neurological and behavioural disorders associated with hyperammonemia at any age and in both genders. Molecular analysis is the method of choice for confirming an OTCD diagnosis, for uncovering the carrier status in at risk family members and for providing genetic counselling and prenatal diagnosis. Future efforts should be aimed at further widening the knowledge about combined effect of genetic factors (i.e. mutations in the OTC gene, variants in modifier genes or epigenetic features) and environmental conditions in determining the phenotypic expression of OTCD.

\section{Availability of supporting data}

The data sets supporting the results of this article are included within the article and its additional files.

\section{Additional files}

Additional file 1: Text S1. Case reports.

Additional file 2: Table S2. Bioinformatic results for the novel p.Arg40Leu and p.Gly105Glu mutations.

\section{Abbreviations}

OTCD: X-linked ornithine transcarbamylase deficiency; UCD: Urea cycle disorder; CP: Carbamyl phosphate; ORN: Ornithine; LO-OTCD: Late onset OTCD; LC-MS/MS: Liquid chromatography-tandem mass spectrometry; Pt: Patient; CPS1: Carbamoyl phosphate synthetase I; NAGS: Nacetylglutamate synthase; MoRF: Molecular recognition feature; MSG: Monosodium glutamate.

\section{Competing interests}

The authors declare that they have no competing interests.

\section{Authors' contributions}

CC participated in the conception and design of the study, performed the molecular genetic studies, contributed to the analysis and interpretation of data and drafted the manuscript. MAD participated in the conception and design of the study, contributed to the analysis and interpretation of clinical and biochemical data and revised the article critically for important

intellectual content. RP, MR, MB, FO, NGS and AC performed the acquisition of clinical findings and contributed to the discussion of data. SF and GLM performed the biochemical assays. SC contributed to the analysis and interpretation of genetic data. EP contributed to the analysis and interpretation of clinical and biochemical data and revised the article critically for important intellectual content. SDM performed the in silico analysis of new mutations and contributed to the discussion of genetic findings. RG contributed to the discussion of clinical data and revised the article critically for important intellectual content. AM participated in the conception and design of the study, coordinated the study, contributed to the analysis and interpretation of data and revised it critically for important intellectual content. All authors read and approved the final manuscript.

\section{Acknowledgements}

We would like to thank the AMMeC (Associazione Malattie Metaboliche Congenite, Italia) and the Fondazione Ospedale Pediatrico A. Meyer ONLUS, Florence, Italy for continuing support. 


\section{Author details}

${ }^{1}$ Molecular and Cell Biology Laboratory, Pediatric Neurology Unit and Laboratories, Neuroscience Department, A. Meyer Children's Hospital, Viale Pieraccini 24, 50139 Florence, Italy. ${ }^{2}$ Metabolic and Muscular Unit, A. Meyer Children's Hospital, Florence, Italy. ${ }^{3}$ Rare Metabolic Diseases Unit, Department of Pediatrics, Fondazione MBBM, San Gerardo Hospital, Monza, Italy. ${ }^{4}$ Department of Medical and Surgical Sciences, University of Bologna, Bologna, Italy. ${ }^{5}$ Intensive Care Unit, S. Maria della Misericordia Hospital, Perugia, Italy. 'Department of Emergency Medicine, School of Medicine, Catholic University of the Sacred Heart, Rome, Italy. ${ }^{7}$ Intensive Care Unit, ASL Salerno 2, Eboli Hospital, Eboli, Italy. ${ }^{8}$ Newborn Screening Biochemistry and Pharmacology Laboratory, Pediatric Neurology Unit and Laboratories, Neuroscience Department, A. Meyer Children's Hospital, Florence, Italy. ${ }^{9}$ Department of Neurosciences, Psychology, Pharmacology and Child Health, University of Florence, Florence, Italy. ${ }^{10}$ Buck Institute for Research on Aging, Novato, CA, USA. ${ }^{11}$ Pediatric Neurology Unit and Laboratories, Neuroscience Department, A. Meyer Children's Hospital, Florence, Italy.

Received: 1 April 2014 Accepted: 27 June 2014

Published: 16 July 2014

\section{References}

1. Brusilow SWHA: Urea Cycle Enzymes. In The Metabolic and Molecular Bases of Inherited Disease. Edited by Scriver CR, Beaudet AL, Valle D, Sly WS. New York: McGraw-Hill; 2001:1909-1963.

2. Numata $S$, Koda $Y$, Ihara $K$, Sawada T, Okano Y, Matsuura T, Endo F, Yoo HW Arranz JA, Rubio V, Wermuth B, Ah Mew N, Tuchman M, Pinner JR, Kirk EP, Yoshino M: Mutant alleles associated with late-onset ornithine transcarbamylase deficiency in male patients have recurrently arisen and have been retained in some populations. J Hum Genet 2010, 55:18-22.

3. Ruegger CM, Lindner M, Ballhausen D, Baumgartner MR, Beblo S, Das A, Gautschi M, Glahn EM, Grunert SC, Hennermann J, Hochuli M, Huemer M, Karall D, Kölker S, Lachmann RH, Lotz-Havla A, Möslinger D, Nuoffer JM, Plecko B, Rutsch F, Santer R, Spiekerkoetter U, Staufner C, Stricker T, Wijburg FA, Williams M, Burgard P, Häberle J: Cross-sectional observational study of 208 patients with non-classical urea cycle disorders. J Inherit Metab Dis 2014, 37:21-30.

4. Haberle J, Boddaert N, Burlina A, Chakrapani A, Dixon M, Huemer M, Karall D, Martinelli D, Crespo PS, Santer R, Servais A, Valayannopoulos V, Lindner $M$, Rubio V, Dionisi-Vici C: Suggested guidelines for the diagnosis and management of urea cycle disorders. Orphanet J Rare Dis 2012, 7:32.

5. Summar ML, Barr F, Dawling S, Smith W, Lee B, Singh RH, Rhead WJ, Sniderman King L, Christman BW: Unmasked adult-onset urea cycle disorders in the critical care setting. Crit Care Clin 2005, 21:S1-S8.

6. Lichter-Konecki U, Nadkarni V, Moudgil A, Cook N, Poeschl J, Meyer MT, Dimmock D, Baumgart S: Feasibility of adjunct therapeutic hypothermia treatment for hyperammonemia and encephalopathy due to urea cycle disorders and organic acidemias. Mol Genet Metab 2013, 109:354-359.

7. La Marca G, Casetta B, Zammarchi E: Rapid determination of orotic acid in urine by a fast liquid chromatography/tandem mass spectrometric method. Rapid Commun Mass Spectrom 2003, 17:788-793.

8. Bisanzi S, Morrone A, Donati MA, Pasquini E, Spada M, Strisciuglio P, Parenti G, Parini R, Papadia F, Zammarchi E: Genetic analysis in nine unrelated Italian patients affected by OTC deficiency: detection of novel mutations in the OTC gene. Mol Genet Metab 2002, 76:137-144.

9. Frishman D, Argos P: Knowledge-based protein secondary structure assignment. Proteins 1995, 23:566-579.

10. Capriotti E, Fariselli P, Casadio R: I-Mutant2.0: predicting stability changes upon mutation from the protein sequence or structure. Nucleic Acids Res 2005, 33:W306-W310.

11. Shi D, Morizono H, Ha Y, Aoyagi M, Tuchman M, Allewell NM: 1.85-A resolution crystal structure of human ornithine transcarbamoylase complexed with N-phosphonacetyl-L-ornithine. Catalytic mechanism and correlation with inherited deficiency. J Biol Chem 1998, 273:34247-34254.

12. Shi D, Morizono H, Yu X, Tong L, Allewell NM, Tuchman M: Human ornithine transcarbamylase: crystallographic insights into substrate recognition and conformational changes. Biochem J 2001, 354:501-509.

13. Sobolev V, Sorokine A, Prilusky J, Abola EE, Edelman M: Automated analysis of interatomic contacts in proteins. Bioinformatics 1999, 15:327-332.
14. Katoh K, Kuma K, Toh H, Miyata T: MAFFT version 5: improvement in accuracy of multiple sequence alignment. Nucleic Acids Res 2005, 33:511-518.

15. Ashkenazy H, Erez E, Martz E, Pupko T, Ben-Tal N: ConSurf 2010: calculating evolutionary conservation in sequence and structure of proteins and nucleic acids. Nucleic Acids Res 2010, 38:W529-W533.

16. Oppliger Leibundgut EO, Liechti-Gallati S, Colombo JP, Wermuth B: Ornithine transcarbamylase deficiency: new sites with increased probability of mutation. Hum Genet 1995, 95:191-196.

17. Tuchman M, Plante RJ, McCann MT, Qureshi AA: Seven new mutations in the human ornithine transcarbamylase gene. Hum Mutat 1994, 4:57-60.

18. Yamaguchi S, Brailey LL, Morizono H, Bale AE, Tuchman M: Mutations and polymorphisms in the human ornithine transcarbamylase (OTC) gene. Hum Mutat 2006, 27:626-632

19. Van Diggelen OP, Zaremba J, He W, Keulemans JL, Boer AM, Reuser AJ, Ausems MG, Smeitink JA, Kowalczyk J, Pronicka E, Rokicki D, TarnowskaDziduszko E, Kneppers AL, Bakker E: Asymptomatic and late-onset ornithine transcarbamylase (OTC) deficiency in males of a five-generation family, caused by an A208T mutation. Clin Genet 1996, 50:310-316.

20. Finkelstein JE, Hauser ER, Leonard CO, Brusilow SW: Late-onset ornithine transcarbamylase deficiency in male patients. J Pediatr 1990, 117:897-902.

21. Rimbaux S, Hommet C, Perrier D, Cottier JP, Legras A, Labarthe F, Lemarcis $L$, Autret A, Maillot F: Adult onset ornithine transcarbamylase deficiency: an unusual cause of semantic disorders. J Neurol Neurosurg Psychiatry 2004, 75:1073-1075.

22. Rowe PC, Newman SL, Brusilow SW: Natural history of symptomatic partial ornithine transcarbamylase deficiency. N Engl J Med 1986, 314:541-547.

23. Cavicchi C, Malvagia S, La Marca G, Gasperini S, Donati MA, Zammarchi E, Guerrini R, Morrone A, Pasquini E: Hypocitrullinemia in expanded newborn screening by LC-MS/MS is not a reliable marker for ornithine transcarbamylase deficiency. J Pharm Biomed Anal 2009, 49:1292-1295.

24. Tuchman M, Holzknecht RA: Heterogeneity of patients with late onset ornithine transcarbamylase deficiency. Clin Invest Med 1991, 14:320-324.

25. Snodgrass PJ: Ornithine Transcarbamylase: Basic Science and Clinical Considerations. Boston: Kluwer Academic Publishers; 2004.

26. Thurlow VR, Asafu-Adjaye M, Agalou S, Rahman Y: Fatal ammonia toxicity in an adult due to an undiagnosed urea cycle defect: under-recognition of ornithine transcarbamylase deficiency. Ann Clin Biochem 2010, 47:279-281.

27. Ihara K, Yoshino M, Hoshina T, Harada N, Kojima-Ishii K, Makimura M, Hasegawa Y, Watanabe Y, Yamaguchi S, Hara T: Coagulopathy in patients with late-onset ornithine transcarbamylase deficiency in remission state: a previously unrecognized complication. Pediatrics 2013, 131:e327-e330.

28. Samuel N, Politansky AK, Hoffman R, Itzkovich S, Mandel H: Coagulopathy unmasking hepatic failure in a child with ornithine transcarbamylase deficiency. Isr Med Assoc J 2013, 15:777-779.

29. Watanabe A: Portal-systemic encephalopathy in non-cirrhotic patients: classification of clinical types, diagnosis and treatment. J Gastroenterol Hepatol 2000, 15:969-979.

30. Harada E, Nishiyori A, Tokunaga Y, Watanabe $Y$, Kuriya N, Kumashiro R, Kuno T, Kuromaru R, Hirose S, Ichikawa K, Yoshino M: Late-onset ornithine transcarbamylase deficiency in male patients: prognostic factors and characteristics of plasma amino acid profile. Pediatr Int 2006, 48:105-111.

31. Saudubray JM, Van Den Berghe G, Walter JH: Inborn Metabolic Diseases: Diagnosis and Treatment. fifthth edition. Berlin-Heidelberg: Springer-Verlag Gmbh; 2012.

32. Mohan A, Oldfield CJ, Radivojac P, Vacic V, Cortese MS, Dunker AK, Uversky VN: Analysis of molecular recognition features (MoRFs). J Mol Biol 2006, 362:1043-1059.

33. Lofberg E, Gutierrez A, Wernerman J, Anderstam B, Mitch WE, Price SR, Bergstrom J, Alvestrand A: Effects of high doses of glucocorticoids on free amino acids, ribosomes and protein turnover in human muscle. Eur J Clin Invest 2002, 32:345-353.

34. Atiq M, Holt AF, Safdar K, Weber F, Ravinuthala R, Jonas ME, Neff GW: Adult onset urea cycle disorder in a patient with presumed hepatic encephalopathy. J Clin Gastroenterol 2008, 42:213-214.

35. Hawley RJ: Hyperammonia possibly due to corticosteroids. Arch Neurol 2000, 57:1085-1086.

36. Lipskind S, Loanzon S, Simi E, Ouyang DW: Hyperammonemic coma in an ornithine transcarbamylase mutation carrier following antepartum corticosteroids. J Perinatol 2011, 31:682-684 
37. Chiong MA, Bennetts BH, Strasser SI, Wilcken B: Fatal late-onset ornithine transcarbamylase deficiency after coronary artery bypass surgery. Med J Aust 2007, 186:418-419.

38. Hu WT, Kantarci OH, Merritt JL 2nd, McGrann P, Dyck PJ, Lucchinetti CF, Tippmann-Peikert M: Ornithine transcarbamylase deficiency presenting as encephalopathy during adulthood following bariatric surgery. Arch Neurol 2007, 64:126-128.

39. Marcus N, Scheuerman O, Hoffer V, Zilbershot-Fink E, Reiter J, Garty BZ: Stupor in an adolescent following Yom Kippur fast, due to late-onset ornithine transcarbamylase deficiency. Isr Med Assoc J 2008, 10:395-396.

40. Ben-Ari Z, Dalal A, Morry A, Pitlik S, Zinger P, Cohen J, Fattal I, Galili-Mosberg R, Tessler D, Baruch RG, Nuoffer JM, Largiader CR, Mandel H: Adult-onset ornithine transcarbamylase (OTC) deficiency unmasked by the Atkins' diet. J Hepatol 2010, 52:292-295.

41. Zai H, Kusano M, Hosaka H, Shimoyama Y, Nagoshi A, Maeda M, Kawamura O, Mori M: Monosodium L-glutamate added to a high-energy, highprotein liquid diet promotes gastric emptying. Am J Clin Nutr 2009, 89:431-435.

42. Chan JS, Harding CO, Blanke CD: Postchemotherapy hyperammonemic encephalopathy emulating ornithine transcarbamoylase (OTC) deficiency. South Med J 2008, 101:543-545.

43. Winter SS, Rose E, Katz R: Hyperammonemia after chemotherapy in an adolescent with hepatocellular carcinoma. J Pediatr Gastroenterol Nutr 1997, 25:537-540.

44. McGuire PJ, Lee HS, Summar ML: Infectious precipitants of acute hyperammonemia are associated with indicators of increased morbidity in patients with urea cycle disorders. J Pediatr 2013, 163:1705-1710. e1701.

45. Grody WW, Chang RJ, Panagiotis NM, Matz D, Cederbaum SD: Menstrual cycle and gonadal steroid effects on symptomatic hyperammonaemia of urea-cycle-based and idiopathic aetiologies. J Inherit Metab Dis 1994, 17:566-574.

46. Felig DM, Brusilow SW, Boyer JL: Hyperammonemic coma due to parenteral nutrition in a woman with heterozygous ornithine transcarbamylase deficiency. Gastroenterology 1995, 109:282-284.

doi:10.1186/s13023-014-0105-9

Cite this article as: Cavicchi et al: Sudden unexpected fatal encephalopathy in adults with OTC gene mutations-Clues for early diagnosis and timely treatment. Orphanet Journal of Rare Diseases 2014 9:105.

\section{Submit your next manuscript to BioMed Central and take full advantage of:}

- Convenient online submission

- Thorough peer review

- No space constraints or color figure charges

- Immediate publication on acceptance

- Inclusion in PubMed, CAS, Scopus and Google Scholar

- Research which is freely available for redistribution 